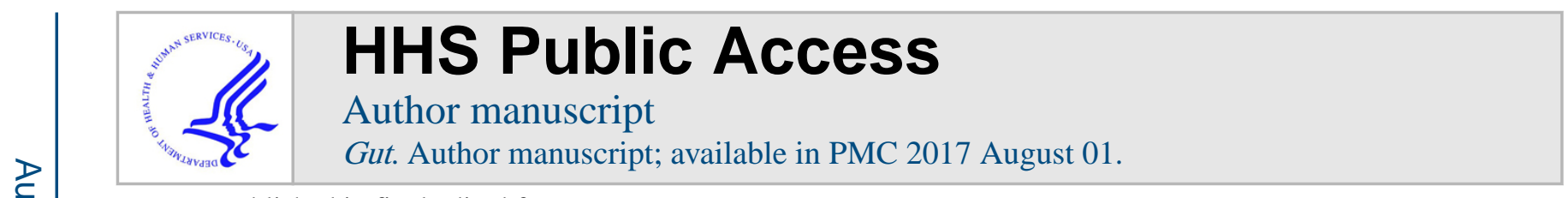

Published in final edited form as:

Gut. 2017 February ; 66(2): 384. doi:10.1136/gutjnl-2016-311823.

\title{
Letter to the editor of Gut
}

Robert P. Dickson ${ }^{1}$ and Michael J. Cox ${ }^{2}$

${ }^{1}$ University of Michigan, Ann Arbor, United States

2 Imperial College London, London, United Kingdom

\section{Dear Editor}

We read with interest the work by Schuijt et aI1] reporting that sustained treatment with broad- spectrum antibiotics increases the susceptibility of mice to pneumococcal pneumonia, an effect that is reversed via faecal microbiota transplantation (FMT). Yet we question the authors' confidence that this effect is entirely attributable to alterations in gut microbiota.

Antibiotic therapy, as used by the authors, alters the microbiota of the upper and lower respiratory tract $[2,3]$. The authors used FMT to determine that the protective effect was due to gut microbiota, yet their protocol for FMT - oral gavage with faecal material - is also a direct manipulation of the microbiota of the upper respiratory tract. Differences in respiratory microbiota correlate strongly with alterations in the abundance and behavior of alveolar inflammatory cells $[4,5]$.

We thus wonder why the authors conclude that the effects of antibiotics and FMT on pneumonia susceptibility were attributable specifically to alterations of lower gastrointestinal tract microbiota. The authors' interventions surely changed the respiratory microbiota of their mice, suggesting a more direct mechanistic explanation. To provide a specific example: the differences reported in the behavior of lung-resident macrophages are plausibly explained by differences in local microbial exposure. Why, then, do the authors conclude uncategorically that "the gut microbiota enhances primary alveolar macrophage function"?

The authors' invocation of a "gut-lung axis" may obscure the importance of local hostmicrobe interactions within the respiratory tract, which require fewer mechanistic assumptions and are of immediate relevance to our understanding of the pathogenesis of pneumonia.

\section{References}

1. Schuijt TJ, Lankelma JM, Scicluna BP, de Sousa e Melo F, Roelofs JJTH, de Boer JD, et al. The gut microbiota plays a protective role in the host defence against pneumococcal pneumonia. Gut. 2016; 65:575-83. [PubMed: 26511795]

2. Slater M, Rivett DW, Williams L, Martin M, Harrison T, Sayers I, et al. The impact of azithromycin therapy on the airway microbiota in asthma. Thorax. 2014; 69:673-4. [PubMed: 24287164]

3. Rogers GB, Bruce KD, Martin ML, Burr LD, Serisier DJ. The effect of long-term macrolide treatment on respiratory microbiota composition in non-cystic fibrosis bronchiectasis: an analysis from the randomised, double-blind, placebo-controlled BLESS trial. Lancet Respir Med. 2014; 2:988-96. [PubMed: 25458200] 
4. Segal LN, Alekseyenko AV, Clemente JC, Kulkarni R, Wu B, Gao Z, et al. Enrichment of lung microbiome with supraglottic taxa is associated with increased pulmonary inflammation. Microbiome. 2013; 1:19. [PubMed: 24450871]

5. Gollwitzer ES, Saglani S, Trompette A, Yadava K, Sherburn R, McCoy KD, et al. Lung microbiota promotes tolerance to allergens in neonates via PD-L1. Nat Med. 2014; 20:642-7. [PubMed: 24813249] 